Supporting Information

for

\title{
Antibody-Conjugated Vitamin E-derived Liposomes for Targeted Gene Transfer
}

Mohini Kamra, ${ }^{\dagger,+}$ Bappa Maiti, ${ }^{\#}$ Pranay Saha, ${ }^{\#}$ Anjali A. Karande ${ }^{\S}$ and Santanu Bhattacharya ${ }^{*,+, \#}$

${ }^{\dagger}$ Department of Organic Chemistry, Indian Institute of Science, Bangalore-560012, India

Technical Research Centre, Indian Association for the Cultivation of Science, Kolkata 700032, India.

\#School of Applied and Interdisciplinary Sciences, Indian Association for the Cultivation of Science, Kolkata 700032, India.

${ }^{\S}$ Department of Biochemistry, Indian Institute of Science, Bangalore 560012, India.

*Correspondence: Santanu Bhattacharya

Professor, School of Applied and Interdisciplinary Sciences,

Director, Indian Association for the Cultivation of Science,

Kolkata 700032, INDIA

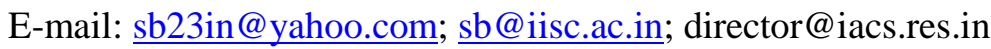




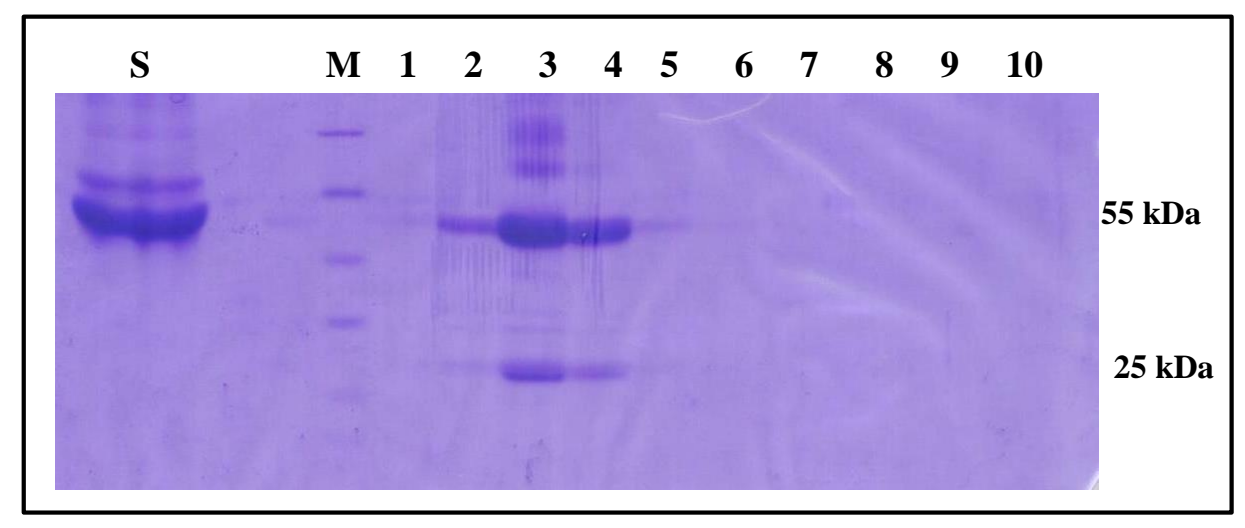

Figure S1. SDS-PAGE of eluted fractions of Protein-A column for anti-LDLr antibody. Lane S: BSA standard; lane M: protein molecular weight marker; lanes 1-10: Fractions 1-10 eluted using $100 \mathrm{mM}$ Glycine. $\mathrm{HCl}, \mathrm{pH} 2.5$ followed by neutralization with $1 \mathrm{M}$ Tris, $\mathrm{pH} 8$.

\section{Scheme $\mathbf{S 1}^{\mathrm{a}}$.}
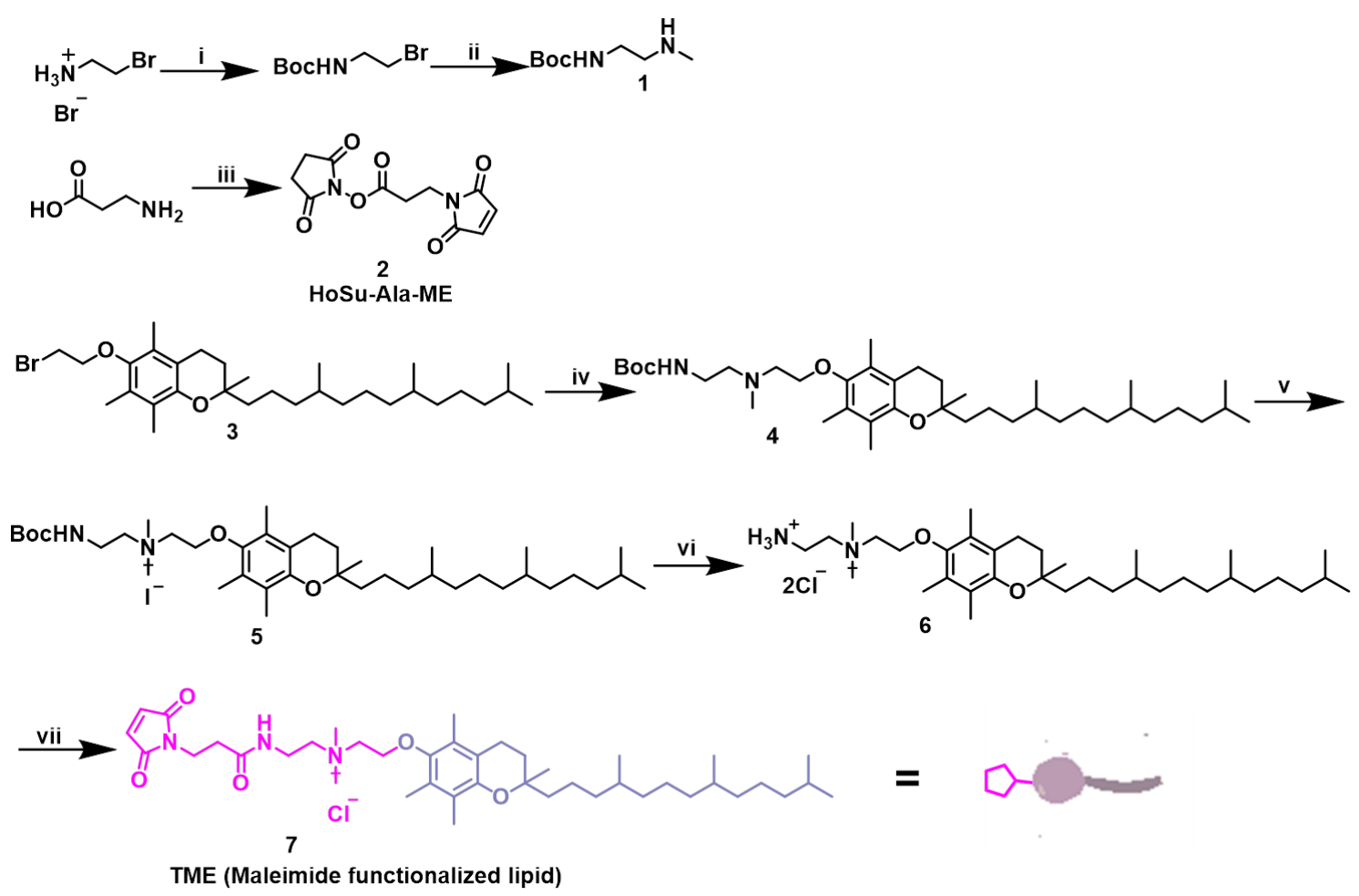

${ }^{a}$ Reagents, conditions and yields. i) $\mathrm{Boc}_{2} \mathrm{O}$, DCM, $\mathrm{Et}_{3} \mathrm{~N}, 90 \%$; ii) $\mathrm{K}_{2} \mathrm{CO}_{3}$, $\mathrm{KI}$ (cat), $\mathrm{CH}_{3} \mathrm{CN}, \mathrm{MeNH}_{2}$, 70\%; iii) (a) maleic anhydride, DMF, 5h (b) DCC, N-hydroxy succinimide, rt, 12 h, 65\%; iv) 1, $\mathrm{CH}_{3} \mathrm{CN}, \mathrm{K}_{2} \mathrm{CO}_{3}, 80{ }^{\circ} \mathrm{C}$, reflux, $24 \mathrm{~h}, \mathrm{~N}_{2}$-atm, 60\%; v) MeI, $\mathrm{K}_{2} \mathrm{CO}_{3}$, THF, rt, $78 \%$; vi) $4 \mathrm{~N} \mathrm{HCl}$ in dioxane, $90 \%$; vii) $2, \mathrm{Et}_{3} \mathrm{~N}, \mathrm{DCM}, \mathrm{rt}, 65 \%$. 


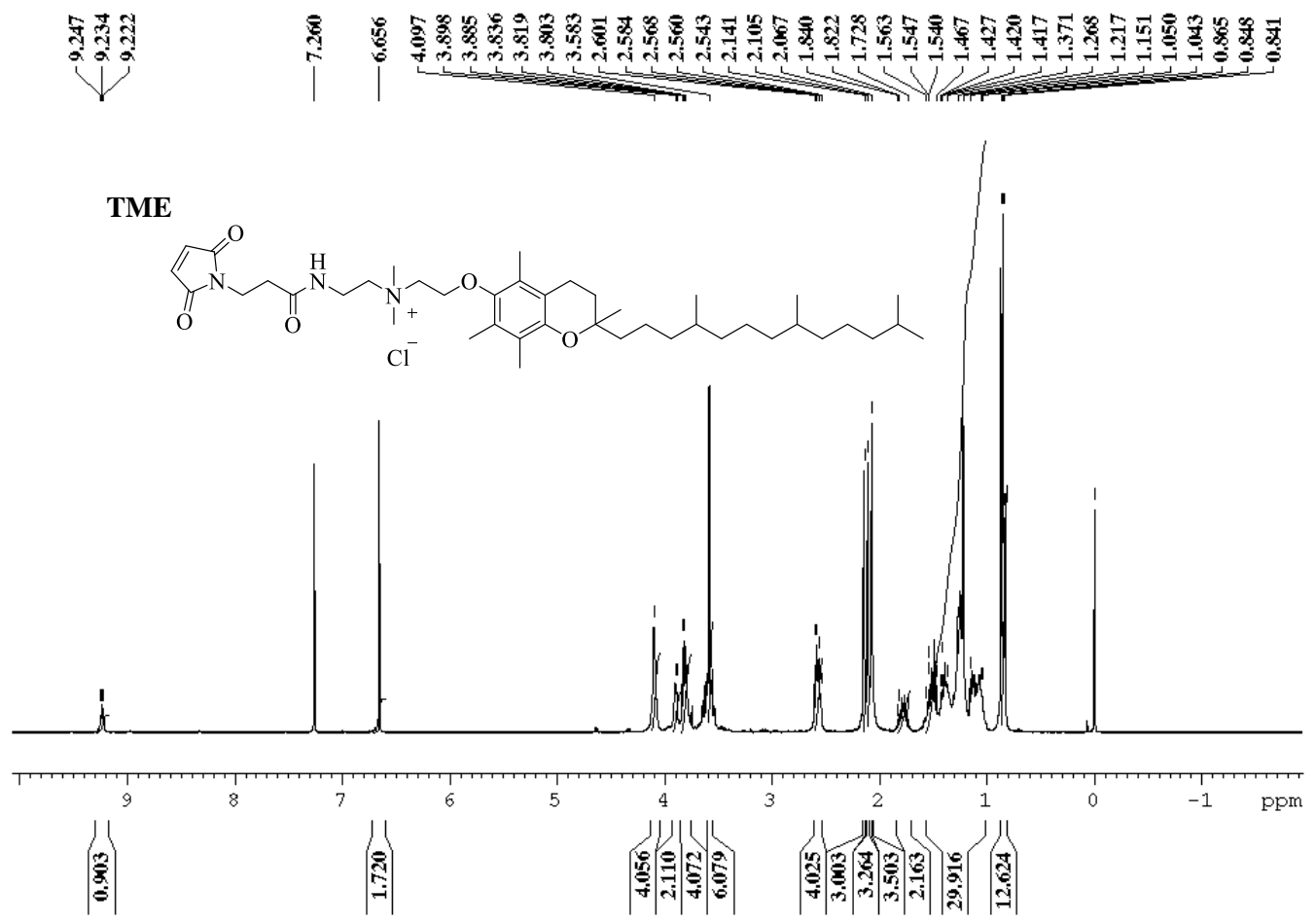

Figure S2. ${ }^{1} \mathrm{H}-\mathrm{NMR}$ of maleimide headed tocopherol (TME)

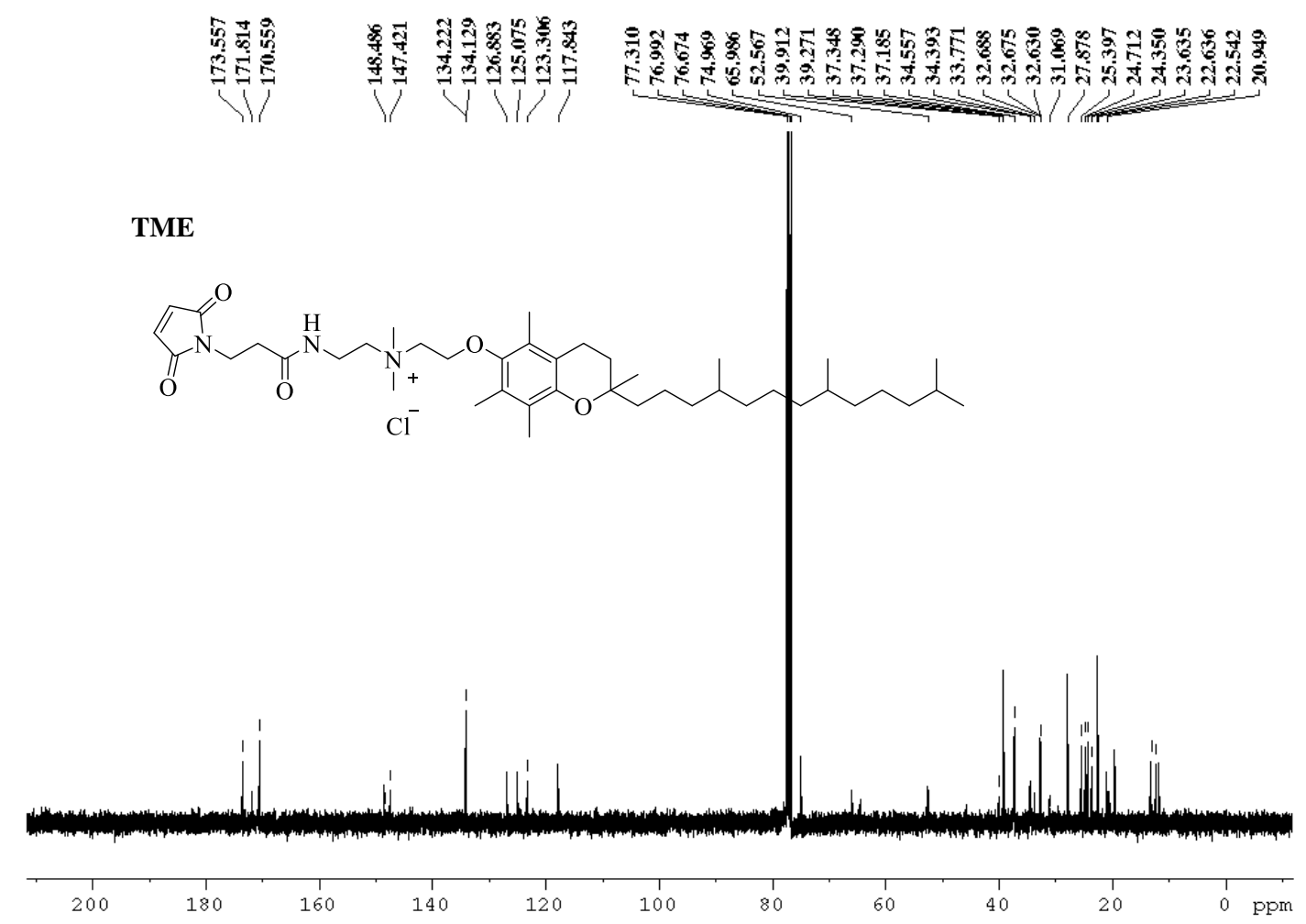

Figure S3. ${ }^{13} \mathrm{C}$-NMR of maleimide headed tocopherol (TME). 
A

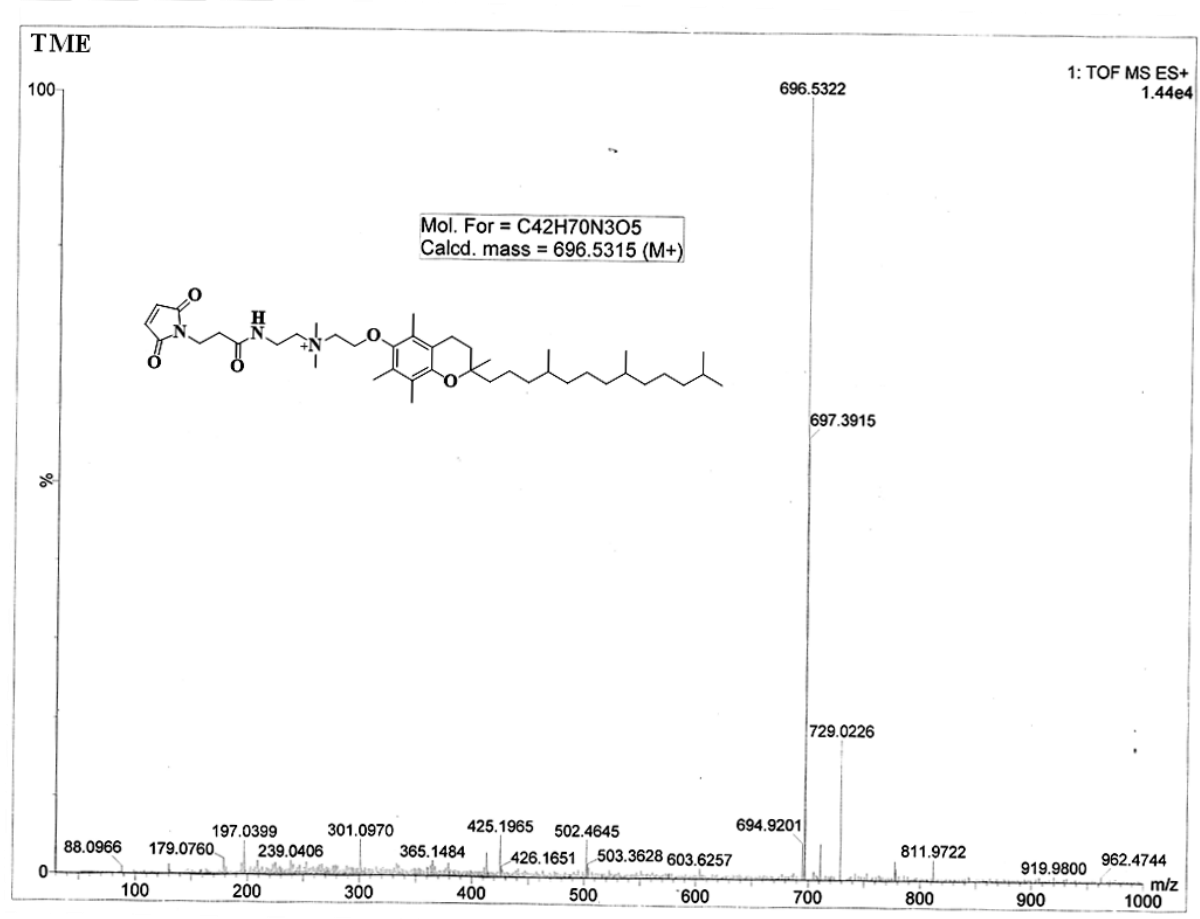

B

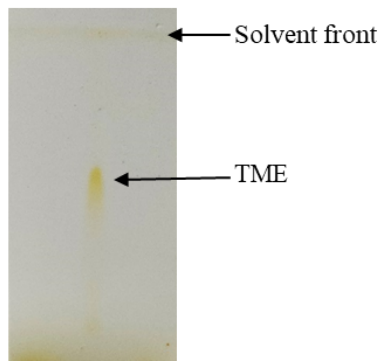

Figure S4. (A) HRMS of maleimide headed tocopherol (TME). (B) Thin layer chromatography (TLC) analysis of TME on silica gel coated aluminum TLC plate, running solvent $\mathrm{CHCl}_{3}: \mathrm{MeOH}^{\mathrm{v} / \mathrm{v}}$ $88: 12)$.

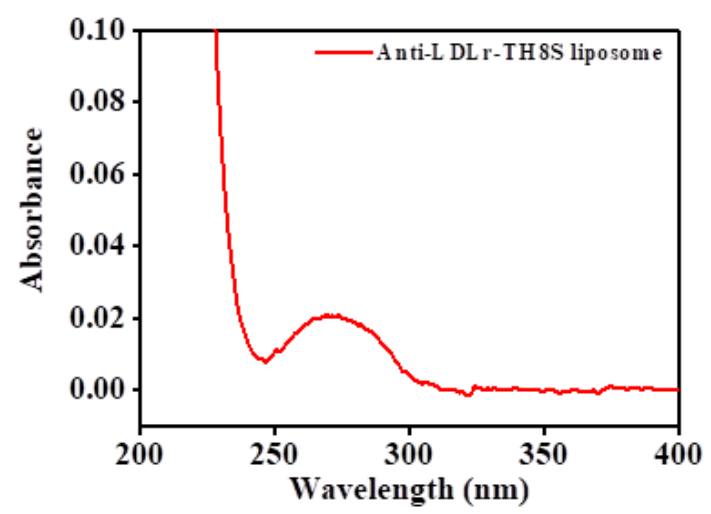

Figure S5. Absorption spectrum of the anti-LDLr tagged TH8S liposomes $(0.15 \mathrm{mM})$. 

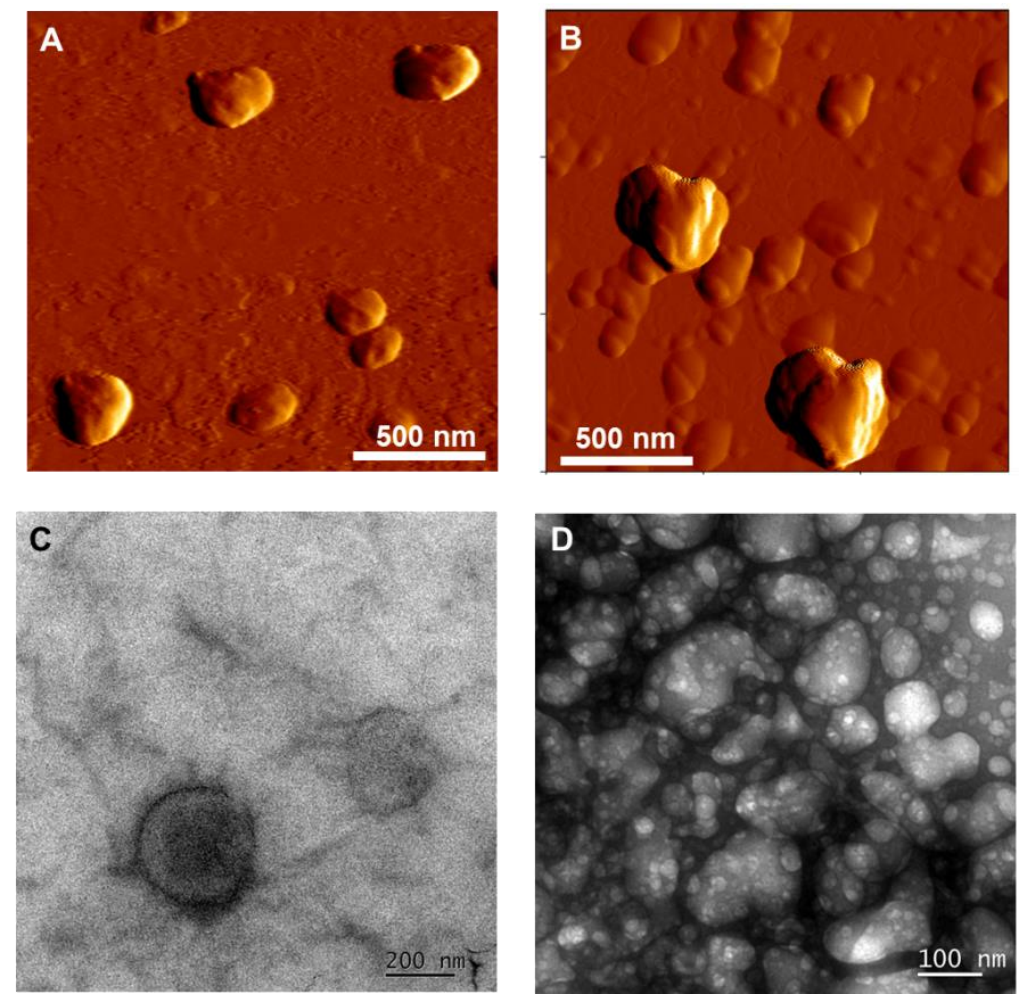

Figure S6. Morphological characterization via AFM (A-B) and TEM (C-D) Panels A,C: 10 mole\% TME containing TH8S liposomes; B,D: anti-LDLr mAb tagged liposomes.

A

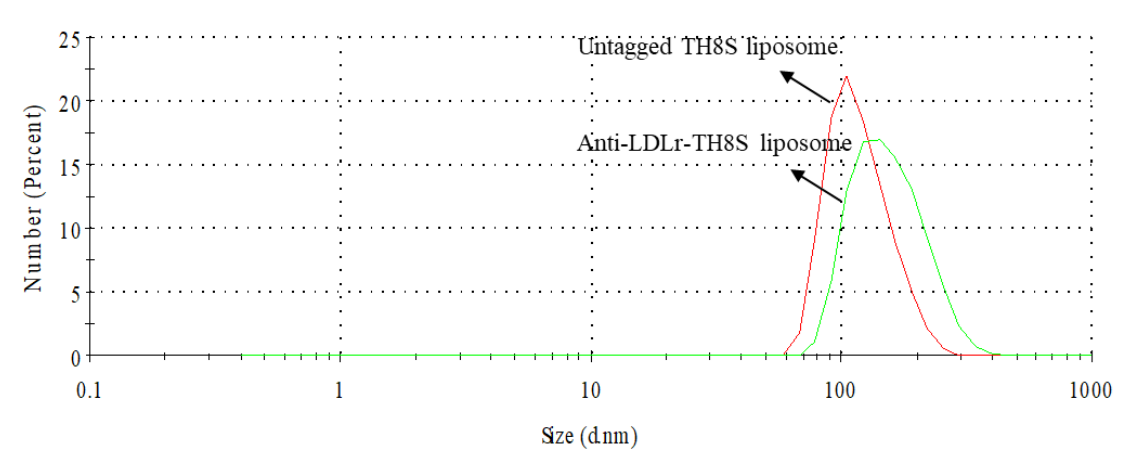

B

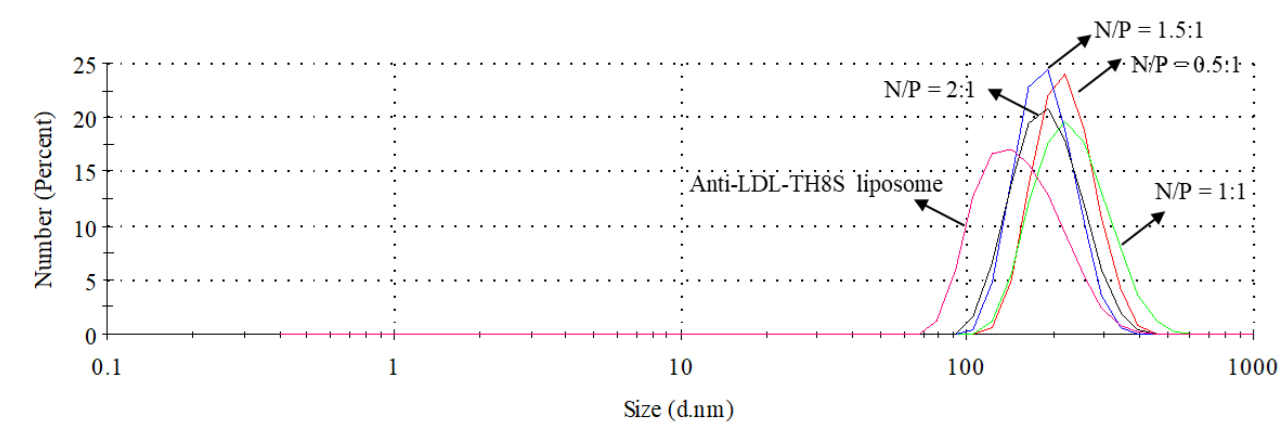

Figure S7. (A) The size distribution of untagged TH8S (without anti-LDLr) and anti-LDLr-TH8S liposome in $\mathrm{pH} 7.4$ buffer. (B) Size distribution of anti-LDLr-TH8S liposome and anti-LDLr-TH8S lipoplexes at different N/P ratios. 
A
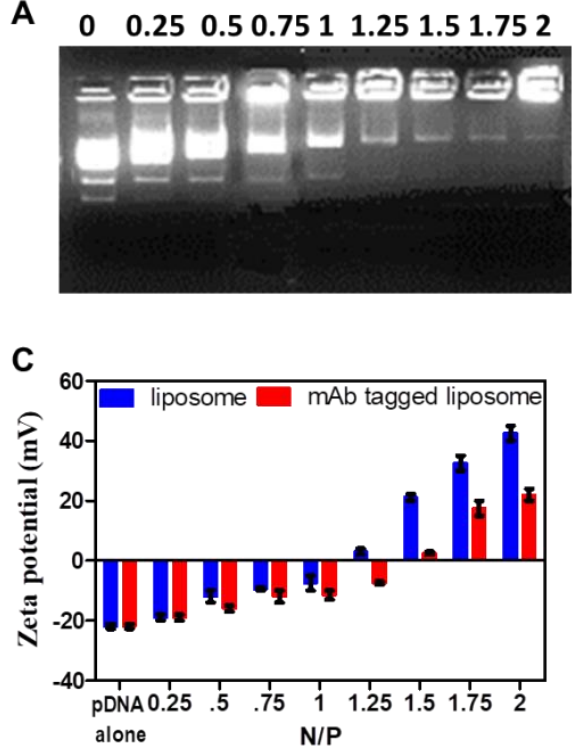

B
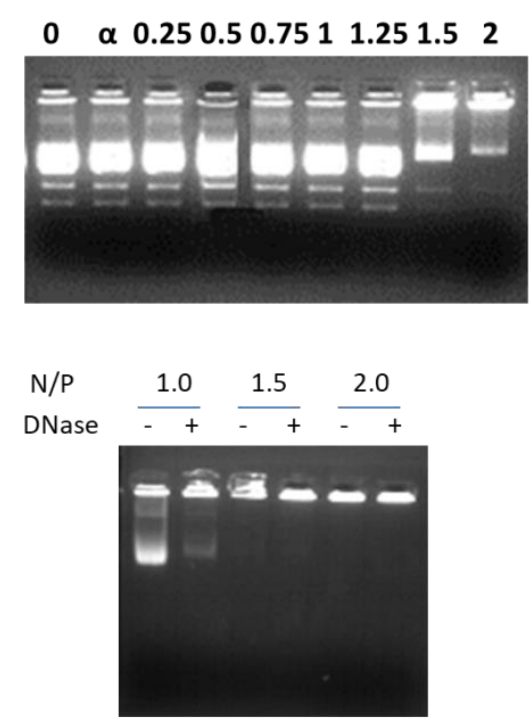

Figure S8. Mobility shift assay for DNA binding of (A) TH8S/TME liposomes and (B) $\alpha$-LDLr mAb tagged TH8S/TME liposomes. [Lane 1: pDNA alone, Lanes 2-9: N/P $=0.25,0.5,0.75,1,1.25,1.5$, 1.75, 2 respectively] (C) Zeta titration of pDNA with increasing N/P of plain liposome and mAb tagged liposome. (D) DNAse protection ability of the mAb tagged TH8S liposomes. $1 \mu \mathrm{g}$ DNA was complexed with the antibody decorated liposomes at different N/P ratios and exposed to DNase I. The resulting formulations were run on agarose gel to assess integrity of DNA under an electrophoretic field of $80 \mathrm{~V}$.

A

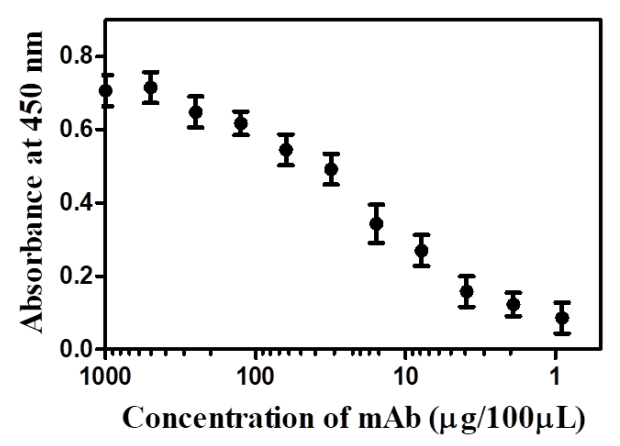

B

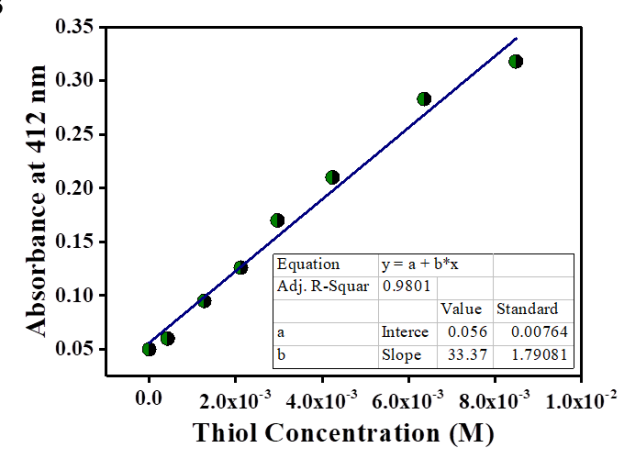

Figure S9. Calibration curves for (A) anti-LDLr mAb plotted using Sandwich ELISA. Anti-Mouse IgG (whole molecule) was coated overnight, followed by probing with anti-LDLr mAb at varying dilutions and HRP conjugated secondary antibody. Absorbance was recorded using reaction with TMB substrate. (B) measuring free thiol concentration using Cysteine and Ellman's reagent in PBS. 

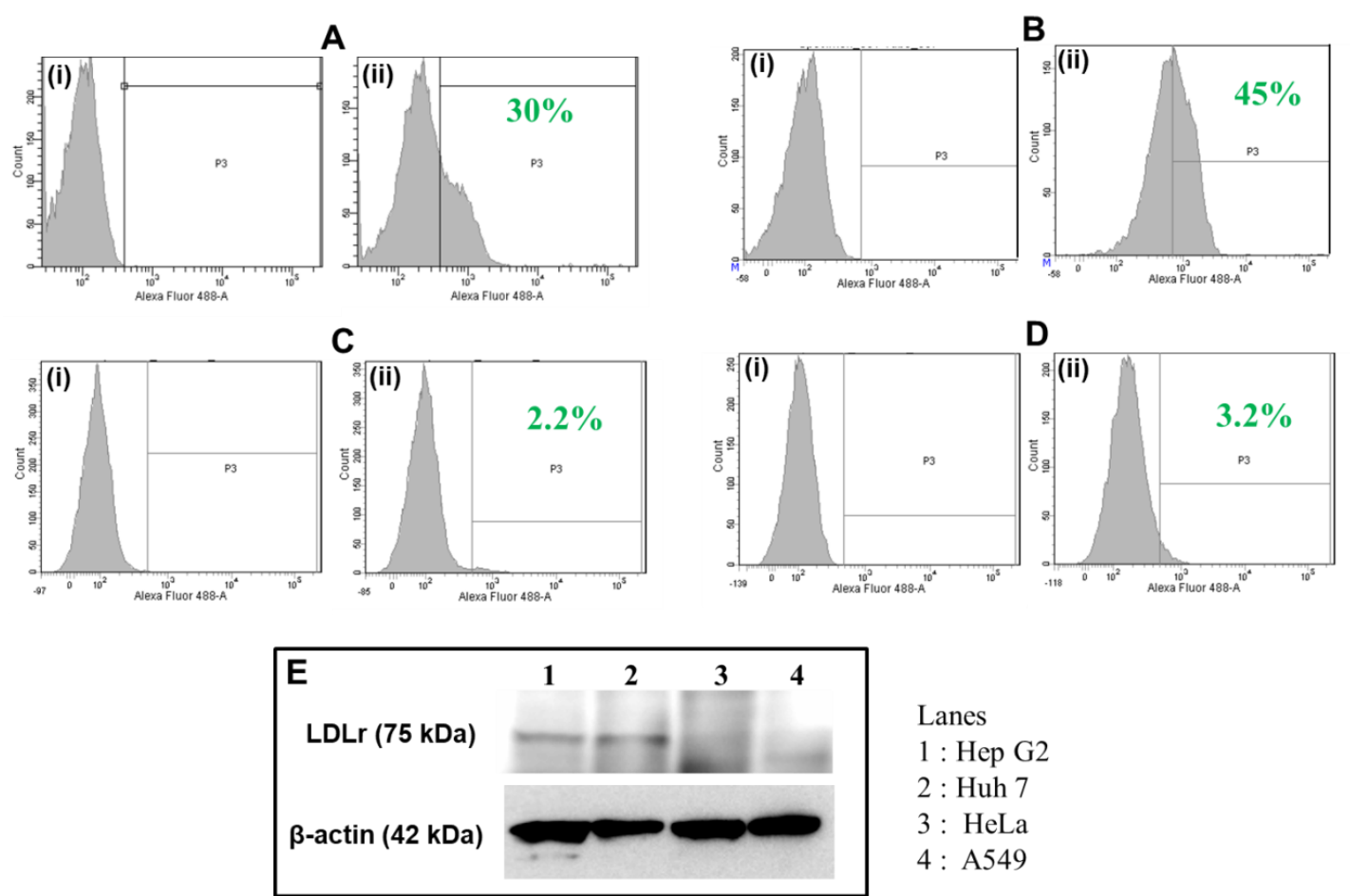

Figure S10. Expression profiling of LDLr. Flow cytometric study for cell surface abundance of LDLr. Histograms for different cell lines are shown as: (A) HepG2; (B) Huh7; (C) HeLa; (D) A549 where panels (i) and (ii) represent the unstained control and immunostained cells (Alexa Fluor 488 labelled anti-LDLr mAb) respectively (E) Western blot analysis, Lanes 1, 2, 3, and 4 represent HepG2, Huh7, HeLa and A549 cell lysates respectively.
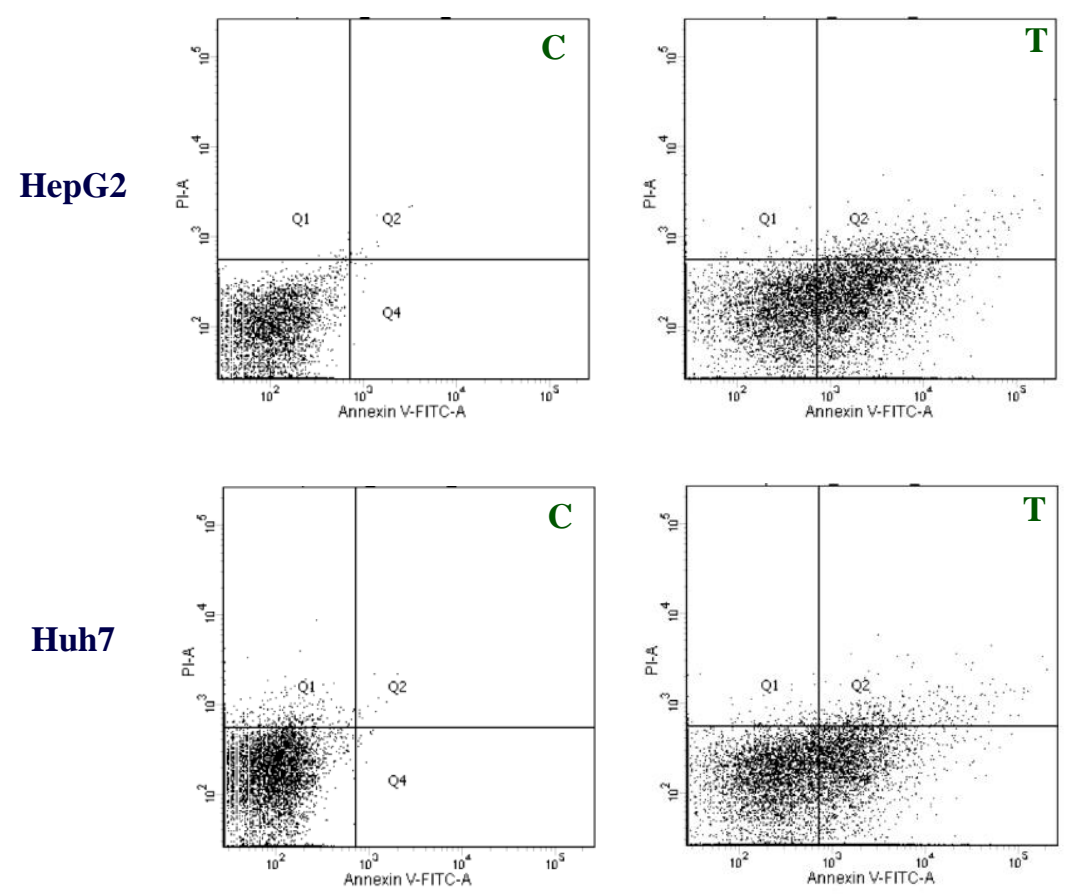

Figure S11. Induction of apoptosis in hepatocellular carcinoma cell lines (C) by pCEP4-p53 plasmid transfected using anti-LDLr tagged TH8S liposomes (T). Quadrants Q1, Q2, Q3 and Q4 represent necrotic, late apoptotic, healthy and early apoptotic population respectively. 
Table S1. Avg. hydrodynamic diameters of the designed formulations

\begin{tabular}{|c|c|c|}
\hline Formulations $^{[\mathbf{a}]}$ & Size (nm) & PDI \\
\hline $\begin{array}{c}\text { Untagged TH8S } \\
\text { liposomes }\end{array}$ & $150 \pm 8$ & $0.2 \pm 0.02$ \\
\hline $\begin{array}{c}\text { Anti-LDLr-TH8S } \\
\text { liposomes }\end{array}$ & $209 \pm 10$ & $0.22 \pm 0.03$ \\
\hline
\end{tabular}

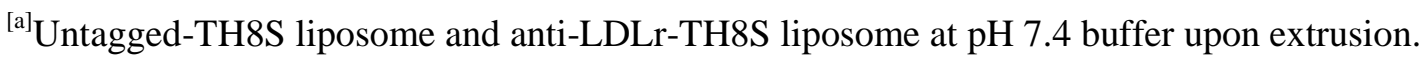

